Thorax, 1978, 33, 818-819

\title{
Thoracic actinomycosis presenting with peripheral skin lesions
}

\author{
A K WEBB, R HOWELL, AND J A HICKMAN \\ From the London Hospital (Whitechapel), London EI 1BB, UK
}

Blood-borne spread of actinomycosis to the skin is rare. We report a patient with intrathoracic actinomycosis who presented with cutaneous lesions on the chest and both legs.

\section{Case report}

A male 30-year-old computer programmer presented to his general practitioner in April with dyspnoea on climbing one flight of stairs, night sweats, non-productive cough, and a loss of $6.35 \mathrm{~kg}$ over a three-month period. During early August he developed pain and swelling in his right calf muscle and the overlying skin was reddened; shortly after this he developed a fluctuant swelling over the lower right chest wall. Chest radiography at that time showed dense shadowing in the right upper zone above the clavicle. A biopsy specimen was taken from the right calf muscle and was reported as showing a picture consistent with a chronic myositis. The abscess from the chest wall was drained, and examination for acid-fast bacilli and bacteria gave negative results. He developed a third skin lesion $2 \mathrm{~cm} \times 3 \mathrm{~cm}$ on his left leg adjacent to the distal third of the tibia. It was firm, raised, red, and tender.

At the beginning of September he was admitted to hospital for further investigation. He was pale and thin, with enlarged lymph nodes in both groins. The wound from the biopsy site on the right calf was breaking down and discharging a serosanguinous fluid. The skin near the incision site was blue. The lesion on the chest wall had healed, but the lesion on the left shin was increasing in size. Examination of the other systems showed no abnormal findings.

Investigations: $\mathrm{Hb} 10 \mathrm{~g} / \mathrm{dl}, \mathrm{WBC} 11000$; differential: neutrophils $70 \%$, lymphocytes $26 \%$, monocytes $4 \%$. ESR $70 \mathrm{~mm}$ in 1 hour. Electrophoresis; diffuse increase in gammaglobulins. Quantitative immunoglobulins; IgG $1153 \mathrm{mg} / 100 \mathrm{ml}$ (N 50$170 \mathrm{mg} / 100 \mathrm{ml}$ ), IgM $1212 \mathrm{mg} / 100 \mathrm{ml}$ (N 50$180 \mathrm{mg} / 100 \mathrm{ml}), \operatorname{IgA} 536 \mathrm{mg} / 100 \mathrm{ml}$ (N 20-55 mg/ $100 \mathrm{ml}$ ). Auto-antibodies; all negative. $\mathrm{C}_{3}$ 190/ $100 \mathrm{ml}(\mathrm{N} 64-145 \mathrm{mg} / 100 \mathrm{ml}) \mathrm{C}_{4} 72 \mathrm{mg} / 100 \mathrm{ml}$ (N $20-55 \mathrm{mg} / 100 \mathrm{ml}$ ). Mantoux weakly positive $1: 1000$, negative $1: 10000$. Multiple cultures of blood, urine, and the discharge from the right leg did not grow pathogenic bacteria, fungi, or tubercle bacilli. No definitive diagnosis could be reached. Punch biopsy of the lesion on the left shin showed infiltration with monocytes and lymphocytes, which were chiefly perivascular but were also present around a hair follicle. The features were consistent with an allergic vasculitis. A lung biopsy of the thoracic lesion was arranged but before this was actually performed further sections of the chest wall lesion were examined; one of these showed fibrous tissue in which was a small abscess consisting of polymorphs surrounding colonies of micro-organisms, which had a central solid area from which were radiating short filaments with clubbed ends representing the sulphur granule seen in pus from actinomycotic lesions. A Gram stain on the serous fluid from one of the wounds showed Gram-positive pleomorphic branched rods; unfortunately multiple anaerobic cultures failed to grow the organism.

After diagnosis the patient was started on intravenous penicillin 2 megaunits 6-hourly for two weeks and then oral penicillin $1 \mathrm{~g}$ four times daily, and it was suggested that treatment should continue for 9-12 months. Six weeks after starting treatment there was some resolution of the apical shadowing; four months later it had resolved further and six months later it had resolved completely.

Retrospectively the patient recalled having visited the dentist at the beginning of the year with painful gums.

\section{Discussion}

Actinomycosis is not uncommon (British Medical Journal, 1977). An average of 40 cases are reported in Britain each year, and the diagnosis may be strongly suspected when the infection spreads by direct extension through tissue planes to form a sinus with the skin surface. The three primary sites of infection are usually the cervicofacial region, the abdomen, and the thorax. Thoracic actinomycosis without a sinus is a difficult diagnosis to make; the chest radiograph has no characteristic appearance and rib involvement is 
now considered to be uncommon (Frank and Strickland, 1974). Further, Actinomyces is a normal mouth commensal, and therefore sputum culture may not help when thoracic actinomycosis is suspected. Exploratory thorocotomy may even be needed to exclude bronchial carcinoma as an alternative diagnosis. Disseminated actinomycosis israelii from a primary source by the blood stream is extremely rare but is thought to occur more commonly with thoracic actinomycosis (Varkey et $a l, 1974)$. Awareness of this unusual manifestation may facilitate early diagnosis when coupled with appropriate anaerobic culture of the material for actinomycosis and also examination of the material for sulphur granules.
We are grateful to Dr Eraut for referring the patient and to Dr Mollin for advice on the histopathology.

\section{References}

Frank, P, and Strickland, B (1974). Pulmonary actinomycosis. British Journal of Radiology, 47, 373-378.

Public Health Laboratory Service (1977). Actinomycosis in 1976. British Medical Journal, 1, 1037.

Varkey, B, Landis, F B, Tang, T T, and Rose, H D (1974). Thoracic actinomycosis. Dissemination to skin, subcutaneous tissue and muscle. Archives of Internal Medicine, 134, 689-693.

Requests for reprints to: Dr A K Webb, The London Hospital (Whitechapel), London E1 1BB. 